\title{
Early leucine programming on protein utilization and mTOR signaling by DNA methylation in zebrafish (Danio rerio)
}

\author{
Qiang-Sheng Zhu ${ }^{1,2+}$, Jie Wang ${ }^{1,2+}$, Shan $\mathrm{He}^{1,2^{*}}$, Xu-Fang Liang ${ }^{1,2}$, Shuang Xie ${ }^{1,2}$ and Qian-Qian Xiao ${ }^{1,2}$
}

\begin{abstract}
Background: Early nutritional programming affects a series of metabolism, growth and development in mammals. Fish also exhibit the developmental plasticity by early nutritional programming. However, little is known about the effect of early amino acid programming on growth and metabolism.

Methods: In the present study, zebrafish (Danio rerio) was used as the experimental animal to study whether early leucine stimulation can programmatically affect the mechanistic target of rapamycin (mTOR) signaling pathway, growth and metabolism in the later life, and to undercover the mechanism of epigenetic regulation. Zebrafish larvas at 3 days post hatching (dph) were raised with 1.0\% leucine from 3 to $13 \mathrm{dph}$ during the critical developmental stage, then back to normal water for 70 days ( $83 \mathrm{dph}$ ).
\end{abstract}

Results: The growth performance and crude protein content of zebrafish in the early leucine programming group were increased, and consistent with the activation of the mTOR signaling pathway and the high expression of genes involved in the metabolism of amino acid and glycolipid. Furthermore, we compared the DNA methylation profiles between the control and leucine-stimulated zebrafish, and found that the methylation levels of CG-differentially methylated regions (DMGs) and CHH-DMGs of genes involved in mTOR signaling pathway were different between the two groups. With quantitative PCR analysis, the decreased methylation levels of CG type of Growth factor receptorbound protein 10 (Grb10), eukaryotic translation initiation factor 4E (elF4E) and mTOR genes of mTOR signaling pathway in the leucine programming group, might contribute to the enhanced gene expression.

Conclusions: The early leucine programming could improve the protein synthesis and growth, which might be attributed to the methylation of genes in MTOR pathway and the expression of genes involved in protein synthesis and glycolipid metabolism in zebrafish. These results could be beneficial for better understanding of the epigenetic regulatory mechanism of early nutritional programming.

Keywords: Leucine, Early nutritional programming, mTOR singling pathway, Protein synthesis, Glycolipid metabolism, DNA methylation

\footnotetext{
*Correspondence: heshan@mail.hzau.edu.cn

${ }^{\dagger}$ Qiang-Sheng Zhu and Jie Wang contributed equally to this work.

${ }^{1}$ College of Fisheries, Chinese Perch Research Center, Huazhong Agricultural University, Wuhan 430070, China

${ }^{2}$ Innovation Base for Chinese Perch Breeding, Key Lab of Freshwater Animal

Breeding, Ministry of Agriculture, Wuhan 430070, China
}

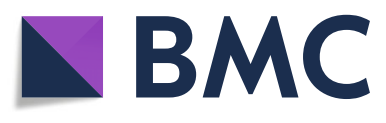

(c) The Author(s). 2020 Open Access This article is licensed under a Creative Commons Attribution 4.0 International License, which permits use, sharing, adaptation, distribution and reproduction in any medium or format, as long as you give appropriate credit to the original author(s) and the source, provide a link to the Creative Commons licence, and indicate if changes were made. The images or other third party material in this article are included in the article's Creative Commons licence, unless indicated otherwise in a credit line to the material. If material is not included in the article's Creative Commons licence and your intended use is not permitted by statutory regulation or exceeds the permitted use, you will need to obtain permission directly from the copyright holder. To view a copy of this licence, visit http://creativecommons.org/licenses/by/4.0/. The Creative Commons Public Domain Dedication waiver (http://creativecommons.org/publicdomain/zero/1.0/) applies to the data made available in this article, unless otherwise stated in a credit line to the data. 


\section{Introduction}

The nutritional programming stimulus exerted at the critical stages of early ontogeny might have persistent consequences on physiological functions in later life stages in mammals [1]. Early nutritional programming is one of the important methods to change the metabolic reaction in later life [2]. Previous studies have been undertaken in fish to determine if the metabolic pathway can be influenced in later life via early nutritional programming [3-6]. At the critical stage of early development of the individual, fish also have significant developmental plasticity by early nutritional programming, as in mammals [7]. Early long-chain n-3 high unsaturated fatty acids programming during the critical developmental stage could have a persistent impact on growth performance and lipid metabolism in later life of Siberian sturgeon (Acipenser baerii Brandt) [8]. In rainbow trout (Oncorhynchus mykiss), early high-carbohydrate diet stimulation has a lasting impact on the genes and enzymes of carbohydrate digestion, glucose transport and metabolism at juvenile stage $[3,9,10]$. However, little is known about the effects of early amino acid programming on growth and nutritional metabolism.

Leucine plays a vital role in protein synthesis and degradation in mammals [11]. The lack or excess of dietary leucine levels reduces the feed utilization and thus affects growth performance in fish [12-14]. In mammals, dietary leucine supplementation has been verified to stimulate protein synthesis via activating the mTOR pathway [11]. Leucine can activate the mTOR signaling pathway in central nervous system of rainbow trout, thereby regulating the digestion and absorption of nutrients [15]. In rainbow trout hepatocytes, leucine stimulation could regulate the mTOR signaling pathway, lipogenesis and gluconeogenesis [16, 17]. However, the knowledge of effect of early leucine programming on nutritional metabolism through mTOR signaling pathway is still limited.

Epigenetic modification is one of the most likely candidates for working on the nutritional programming. Previous researches have mainly focused on the epigenetic regulation mechanisms of nutritional or metabolic programming [18, 19]. DNA methylation is one of the most intensely studied epigenetic modifications, and plays a vital role in the regulation of biological processes, such as cell differentiation, embryogenesis, genomic imprinting and gene expression $[20,21]$. Early methionine programming has been shown to affect the DNA methylation in later life via controlling onecarbon metabolism in mammals [22, 23]. In rainbow trout, the methionine level could be of critical importance in metabolic programming, and modified DNA methylation levels at some specific loci of bnip3a and bnip3lb1 [24]. However, few data are available on epigenetic regulatory mechanisms of early leucine programming in fish.
In the present study, we used the leucine immersion at early stage of development of zebrafish to study whether early leucine stimulation can programmatically affect the mTOR signaling pathway, growth and nutrition metabolism, and to investigate the DNA methylation involved in the early leucine programming. This is the first study to explore the global methylation profile of early amino acid programming in zebrafish. It might provide a theoretical basis for the molecular regulatory mechanisms of early nutritional stimulation on growth and metabolism in later life of animals.

\section{Materials and methods}

\section{Fish and samples}

All zebrafish embryos used in this study were obtained from Institute of Hydrobiology, Chinese Academy of Sciences (Wuhan), and hatched in a $28^{\circ} \mathrm{C}$ incubator. The zebrafish larvas were maintained in the circulating water system at $27-28^{\circ} \mathrm{C}(12 \mathrm{~h}$ light: $12 \mathrm{~h}$ dark photoperiod). The larvas at mouth opening period were fed with egg yolk twice per day, and then a gradual replacement with brine shrimp occurred from $5 \mathrm{dph}$, till the larvas were exclusively fed with brine shrimp, which was one of the general foods for zebrafish. The brine shrimp larvas were purchased from Tianjin Fengnian aquaculture Lit. (Tianjin, China), and hatched in a salty water of $16-17 \%$ at $27 \pm$ $1{ }^{\circ} \mathrm{C}$ for $24 \mathrm{~h}$. The brine shrimp contains $49.6 \%$ of crude protein, $13 \%$ of moisture, $3.4 \%$ of ash, $5.2 \%$ of crude fat. To eliminate the effect of change of diet on gene or protein expression, zebrafish was fed with brine shrimp during the whole experiment period. The zebrafish larvas at $3 \mathrm{dph}$ were randomly assigned into the control group (without programming) and the leucine programming group with three replicates $(n=300)$ for each group. Larvas in the leucine programming group were cultured in the water with $1 \%$ leucine $(\mathrm{pH}=6.8 \pm 0.1)$ for 10 days from 3 to $13 \mathrm{dph}$, and then reared in normal water for 70 days from 13 to 83 $\mathrm{dph}$. The immersion treatments were conducted as a similar manner described by the previous study [25]. The control group was cultured in normal water $(\mathrm{pH}=7.2 \pm 0.1)$ during the whole experiment period. The zebrafish larvas were sampled at 13 and $83 \mathrm{dph}$, respectively. The body weight and total length were measured. The experiments were performed in accordance with the "Guidelines for Experimental Animals" of the Ministry of Science and Technology (Beijing, China). The study was approved by the Institutional Animal Care and Use Ethics Committee of Huazhong Agricultural University. All efforts were made to minimize suffering.

The whole fish (13 dph) were sampled for analyzing leucine content in whole-body of fish with the leucine immersion treatment. The whole-body samples were freeze-dried and finely ground using a grinder, and acid hydrolysis was performed. After filtration with a $0.22 \mu \mathrm{m}$ 
membrane filter, the analysis of leucine was carried out by using A300 amino acid analyzer (membraPure Bodenheim, Germany) [26], with the experiment parameter: sulfonic acid cation resin chromatography column $(4.6 \mathrm{~mm} \times 60.0 \mathrm{~mm})$, column temperature of $57.0^{\circ} \mathrm{C}$, reactor temperature of $130{ }^{\circ} \mathrm{C}$, the flow rate of pump A (elution solution) of $0.40 \mathrm{~mL} / \mathrm{min}$, the flow rate of pump B (ninhydrin solution) of $0.35 \mathrm{~mL} /$ min, the sample volume of $20 \mu \mathrm{L}$, the detection wavelength of $570 \mathrm{~nm}$.

\section{Body composition analysis}

Six zebrafish at $83 \mathrm{dph}$ were randomly selected and stored at $-20^{\circ} \mathrm{C}$, which were used for body composition analysis. The whole-body compositions were determined by the standard methods [27]. The moisture was analyzed by drying at $105^{\circ} \mathrm{C}$ for $6 \mathrm{~h}$. By using the Kjeltec system after acid digestion (K8400 Kjeltec Analyzer, Fossana Lyticab, Sweden), the determination of crude protein $(\mathrm{N} \times 6.25)$ was conducted. The crude lipid was measured by using the ether-extraction with Soxtec System HT (SE-A6, Alvah, China).

\section{Real-time qPCR analysis}

Total RNA was extracted from whole fish $(13 \mathrm{dph})$ and liver tissue (83 dph) using TRIzol reagent (TaKaRa, Japan) and purified for expression analysis of mRNA. Afterwards, total RNA was reverse transcribed via using HiScript II Q RT SuperMix reverse transcriptase (Vazyme, Piscataway, NJ, USA). After complementary DNA (cDNA) synthesis, the expression level of mRNA was detected according to ChamQ SYBR qPCR Master Mix (Vazyme, Piscataway, NJ, USA). Design primers according to Primer5 software, expression levels of mRNA were analyzed by a CFX Maestro real-time detection system (Bio-Rad, USA). Relative gene expression was calculated using the $2^{-\Delta \Delta \mathrm{Ct}}$ method [28], each sample was repeated at least three times. Primers of all genes for Real-time qPCR analysis are listed in Table 1.

\section{Western blot analysis}

The whole fish (13 dph) and liver tissues $(83 \mathrm{dph})$ stored at $-80^{\circ} \mathrm{C}$ were solubilized in RIPA lysis buffer. The protein content was determined using BCA protein assay kit (Yeasen, China). The proteins were separated on $10 \%$ SDS-PAGE gel, and then transferred onto PVDF membrane. Anti-phospho ribosomal protein S6 kinase 1 (S6K1) (Thr389), anti-S6K1, anti-phospho ribosomal protein S6 (S6) (Ser235/236), anti-S6 and anti-phospho Grb10 (Ser476) were purchased from Cell Signalling Technology (USA), anti- $\beta$-actin antibody from Bioss (China), anti- $\beta$-tubulin antibody from Zoman Biotechnology (China). Blots were probed by goat anti-rabbit and goat anti-mouse second antibody with IR-Dye 680
Table 1 Primers of all genes for qRT-PCR are listed

\begin{tabular}{|c|c|c|}
\hline & Sequence $5^{\prime}-3^{\prime}$ & $\operatorname{Tm}\left({ }^{\circ} \mathrm{C}\right)$ \\
\hline \multirow[t]{2}{*}{ acca } & F: GTGGAAACAAAGTTATTGAGAAGG & 55 \\
\hline & R: GTAAGCCCAGCGTCGGA & \\
\hline \multirow[t]{2}{*}{ cpt1 } & F: ATCAGCACTGTTGAGCGAAG & 59 \\
\hline & R: CACTCCСТCCСТАCTTATCTCC & \\
\hline \multirow[t]{2}{*}{ CS } & F: TTCGCTCGGGCGTATTCT & 59 \\
\hline & R: GCTGCTGCCTTCACGGTAT & \\
\hline \multirow[t]{2}{*}{ fas } & F: GATGGACGAGTGCTTTACCC & 55 \\
\hline & R: ATGGTGGCTCTATGGATGGT & \\
\hline \multirow[t]{2}{*}{ got } & F: GCTAAAGGCTTACACCTACTAT & 56 \\
\hline & R: GTCAAAGAACACCAGGAGAT & \\
\hline \multirow[t]{2}{*}{ gpt } & F: AGAAGACCCTGACGATGGAC & 56 \\
\hline & R: GAGGAAGGTGATTGGTTGCT & \\
\hline \multirow[t]{2}{*}{ Pfk1 } & F: AACGAACTCTTCCAAACTCCTG & 55 \\
\hline & R: GACTCCTTCATACGCCTCAAAT & \\
\hline \multirow[t]{2}{*}{ mtor } & F: GCCGCTTTGCCAACTATTT & 55 \\
\hline & R: TCGTCTGCCTTCATTCCTG & \\
\hline \multirow[t]{2}{*}{ leptinA } & F: ATTCCCGCTGACAAACCC & 56 \\
\hline & R: GTAACCCAGAAGTGTGGATAGATC & \\
\hline \multirow[t]{2}{*}{ leptinB } & F: CCCCGTCACCTCCAACTACCT & 59 \\
\hline & R: CAGAGAATGAATGTCTCAGCCACA & \\
\hline \multirow[t]{2}{*}{ grb10 } & F: TCCGAACCCTITCCCTGAG & 60 \\
\hline & R: CTTCCACAACTITTCCCACA & \\
\hline \multirow[t]{2}{*}{$w d r 24$} & F: TTACTGAGCGGCAAACCC & 57 \\
\hline & R: TGATTCGCAGCATCGTCC & \\
\hline \multirow[t]{2}{*}{ eif4e } & F: AGTGATGATGTCTGTGGTGCTG & 61 \\
\hline & R: TGTTCTCGTAGTCTGTCGTCC & \\
\hline \multirow[t]{2}{*}{$\beta$-actin } & F: CACCTTCCAGCAGATGTGGA & 58 \\
\hline & R: AAAAGCCATGCCAATGTTGTC & \\
\hline
\end{tabular}

or $800 \mathrm{cw}$ labeled (Licor, USA) at room temperature for $1 \mathrm{~h}$. The membranes were then visualized using a LiCor Odyssey scanner (Licor, USA) and quantified with ImageJ 1.44 software (National Institute of Health, MD). The phosphorylation level of S6 and S6K1 were normalized according to the loading of proteins by expressing the data as a ratio of phospho-S6 and phospho-S6K1 over S6 and S6K1, respectively. Besides, the phosphorylation level of Grb10 were normalized according to the loading of proteins by expressing the data as a ratio of phospho-Grb10 over $\beta$-actin.

\section{Methylome sequencing}

The genomic DNA was extracted from the liver tissue of zebrafish (83 dph) with a DNA extraction kit (Tiangen, China), and the DNA concentration was determined with a multi-function microplate reader (BioTek, USA). The contamination and degradation of genomic DNA 
was examined with 1\% agarose gel electrophoresis. For whole genome bisulfite sequencing (WGBS) technology library constructing, the genomic DNA was fragmented to an average size of approximately 250 bp by sonication using a Bioruptor (Diagenode, Belgium), followed by end repair and adenylation. Ligated DNA was bisulfite converted using the EZ DNA Methylation-Gold kit (ZYMO). Different insert size fragments were excised from the same lane of a $2 \%$ TAE agarose gel. Products were purified by using QIAquick Gel Extraction kit (Qiagen) and amplified by PCR. Sequencing was performed using HighSeq4000 platforms. The library construction and sequencing were performed by Beijing Genomics Institute (BGI)-Shenzhen (Shenzhen, China).

After filtering adaptor sequences, contamination and lowquality reads, the clean reads data was mapped to the reference genome of zebrafish (Danio rerio assembly GRCz11, https://www.ncbi.nlm.nih.gov/genome/?term=Danio+ rerio\%5Borgn\%5D) by Bisulfite Sequence Mapping Program (BSMAP), and then removed the duplication reads and merged the mapping results according to each library. We calculated the mapping rate and bisulfite conversion rate of each sample. The DMRs between the control group and leucine programming group were identified by comparison of the sample methylomes from two groups using windows that contained at least $5 \mathrm{CpG}(\mathrm{CHG}$ or $\mathrm{CHH}(\mathrm{H}=\mathrm{C}$, T and A)) sites with a 2-fold change in methylation level, and Fisher Test $P$ value $\leq 0.05$. Gene Ontology (GO) and Kyoto Encyclopedia of Genes and Genomes (KEGG) enrichment analysis of genes related to DMRs were considered significantly enriched KEGG and GO terms with corrected $P$ values of less than 0.05 . DNA methylation status of the genes involved in mTOR signaling pathway were displayed by Integrative Genomics Viewer (IGV 2.8.x).

\section{Statistical analysis}

Statistical analyses were performed with SPSS 19.0 software. All data were tested for normality and homogeneity of variances using the Shapiro-Wilk's test and Levene's test, respectively. Significant differences were found using one-way analysis of variance (ANOVA), followed by Fisher's least significant difference post hoc test and Duncan's multiple range tests, after confirming data normality and homogeneity of variances. Differences were considered be significant if $P<0.05$.

\section{Results}

\section{Effects of early leucine programming on growth and body composition}

We analyzed the leucine level in whole-body of zebrafish after early leucine programming at $13 \mathrm{dph}$. The result revealed that the leucine level in zebrafish of the leucine programming group was higher than that of the control group at $13 \mathrm{dph}(P<0.05)$ (Fig. 1). The total length of

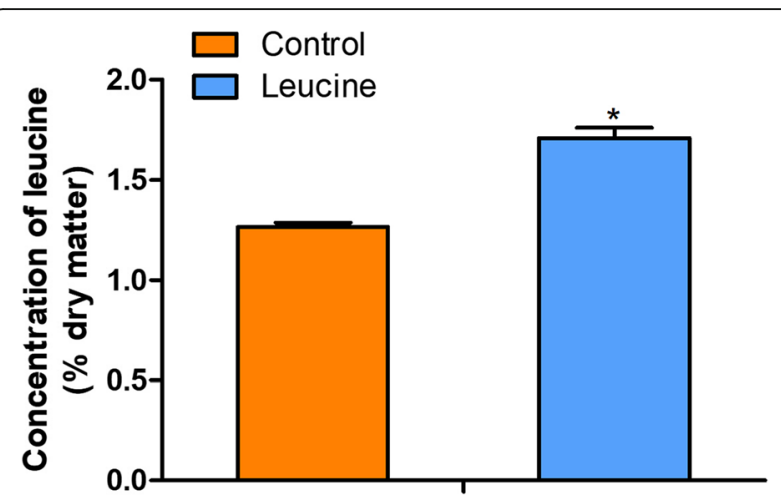

Fig. 1 The leucine level in whole-body of zebrafish after early leucine programming at $13 \mathrm{dph}$. The value represented mean $\pm \mathrm{S}$. E.M. $(n=6)$, marked with an asterisk means significant level $(P<0.05)$

zebrafish in the leucine programming group was higher than that in the control group at $13 \mathrm{dph}(P<0.05)$. Meanwhile, the total length and body weight of zebrafish in the leucine programming group also increased significantly $(P<0.05)$ at $83 \mathrm{dph}$ (Table 2$)$. The content of total water, crude protein and crude lipid were detected in zebrafish larvas at $83 \mathrm{dph}$. The total water content showed no significant difference between the two groups $(P>0.05)$, and the content of total crude protein in the larvas of leucine programming group was significantly increased $(P<0.05)$, whereas the total crude fat was significantly decreased $(P<0.05)$ (Table 3$)$.

\section{Effect of early leucine programming on mTOR signaling pathway}

The phosphorylation status of mTOR downstream factors (S6K1, S6, Grb10) and the mRNA expression of mtor gene were displayed in Fig. 2. At 13 dph, the abundance of phosphorylated S6K1, S6 and Grb10 were increased in the larvas treated with leucine $(P<0.05)$. Furthermore, at $83 \mathrm{dph}$, compared with the control group, leucine programming also leaded to the higher abundance of phosphorylated S6K1 and S6 $(P<0.05)$. The abundance of phosphorylated Grb10 showed no significant difference between the two groups $(P>0.05)$ (Fig. 2a, b, c). Meanwhile, the mRNA expression of $m$ tor gene was analyzed by real-time qPCR, and the mRNA levels of $m$ tor in the leucine programming group were significantly higher than those in the control group at 13 dph and $83 \mathrm{dph}(P<0.05)$ (Fig. 2d).

\section{Expression of genes related to glucose, lipid and protein metabolism}

The expression of genes involved in glucose, lipid and protein metabolism, were analyzed by real-time qPCR (Fig. 3). Compared with the control group, the mRNA levels of carnitine palmitoyl transferaseI (cpt1), phosphofructo kinaseI (pfk1), glutamic-pyruvic transaminase 
Table 2 Growth performance of zebrafish at 13 and 83 dph

\begin{tabular}{llllll}
\hline & $13 \mathrm{dph}$ & & $83 \mathrm{dph}$ & \\
\cline { 2 - 3 } & Control & Leucine & & Control & Leucine \\
\hline Body weight $(\mathrm{mg})$ & - & - & $87.61 \pm 3.10^{\mathrm{a}}$ & $127.67 \pm 2.84^{\mathrm{b}}$ \\
Total length $(\mathrm{mm})$ & $7.36 \pm 0.25^{\mathrm{a}}$ & $7.56 \pm 0.22^{\mathrm{b}}$ & $18.91 \pm 0.35^{\mathrm{a}}$ & $24.11 \pm 0.22^{\mathrm{b}}$ \\
\hline
\end{tabular}

Data represent mean \pm SEM $(n=6)$, values that share different letters are significantly different $(P<0.05)$

(gpt), and leptin $A$ and $B$ of zebrafish larvas in the leucine programming group were significantly higher at 13 dph and $83 \mathrm{dph}(P<0.05)$. The mRNA levels of citrate synthase $(c s)$, acetyl-CoA carboxylase alpha $(a c c \alpha)$ and fatty acid synthase (fas) of fish in the leucine programming group were significantly increased at $83 \mathrm{dph}$ $(P<0.01)$, but no significant difference at $13 \mathrm{dph}$. The abundance of glutamic-oxaloacetic transaminase $(\mathrm{got})$ of fish in the leucine programming group was significantly decreased at $13 \mathrm{dph}(P<0.01)$, but no significant difference at $83 \mathrm{dph}(P>0.05)$.

\section{Bisulfite sequencing and DNA methylation profiling}

To study the genome-wide DNA methylation pattern, we collected the liver tissues from zebrafish in the control group and leucine programming group for constructing genomic DNA libraries. Averagely $30 \mathrm{~Gb}$ clean bases after filtering low-quality reads, $\mathrm{N}$ reads and adaptor sequences were generated. The sequencing data in this study have been deposited in the Sequence Read Archive (SRA) database (accession number: SUB6149613 and PRJNA559591). The BS conversion rates of genomic DNA ranged from 99.44 to $99.51 \%$. The high-quality methylation maps of the two groups were obtained, and the unique mapping rates ranged from 56.10 to $58.48 \%$ (Additional file 1). Proportion in total methyl-cytosine of $\mathrm{mCG}, \mathrm{mCHG}$ and $\mathrm{mCHH}$ was summarized for each sample. In the control group, we detected 24,783,377 $\mathrm{mC}$ sites, 23,647,352 mCG cites (95.42\% of all $\mathrm{mC}$ ), 265, $324 \mathrm{mCHG}$ sites $(1.07 \%$ of all $\mathrm{mC}), 870,701 \mathrm{mCHH}$ sites $(3.51 \%$ of all $\mathrm{mC})$, respectively. Similarly, there were 95.57\% $\mathrm{mCG}, 1.04 \% \mathrm{mCHG}$, and $3.39 \% \mathrm{mCHH}$ in the leucine programming group (Additional file 2).

We computed the average level of genome-wide methylation and found that the genome-wide methylation levels of total cytosine and CG methylation types showed no significant difference between the control and leucine programming group, while those of CHG

Table 3 Body composition analysis of zebrafish at $83 \mathrm{dph}$

\begin{tabular}{lll}
\hline & Control & Leucine \\
\hline Moisture (\%) & $74.14 \pm 0.22$ & $73.59 \pm 0.29$ \\
Crude Protein (\%) & $16.03 \pm 0.17^{\mathrm{a}}$ & $18.27 \pm 0.20^{\mathrm{b}}$ \\
Crude Lipid (\%) & $7.58 \pm 0.09^{\mathrm{a}}$ & $5.12 \pm 0.10^{\mathrm{b}}$ \\
\hline
\end{tabular}

Data represents mean $\pm \operatorname{SEM}(n=6)$, values that share different letters are significantly different $(P<0.05)$ and $\mathrm{CHH}$ methylation types in fish of the leucine programming group were significantly increased (Fig. 4a). To further study the global DNA methylation profile, we analyzed the DNA methylation levels of different genomic regions (Fig. 4b, c, d). The average methylation levels of different genomic regions showed no difference between the two groups. A major proportion of methylated sites were present in the regions of introns, and the average methylation level of CDSs was the lowest. In order to reveal the relationship between DNA methylation profiles and genes expression, we analyzed the DNA methylation profiles of transcriptional units which were divided into functional elements as shown in Additional file 3. Similar tendencies of methylation change were observed in different functional elements between the two groups.

DMRs were stretches of DNA in a sample's genome that have different DNA methylation patterns compared with other samples, a sliding-window approach was used to identify DMRs which contained at least five CG $(\mathrm{CHH}$ or CHG) sites. We identified a total of 199,750, 671 and 8314 DMRs in CG, CHG, and CHH contexts (CHH-DMRs, CHG-DMRs, and CG-DMRs) between zebrafish of the control group and leucine programming group at $83 \mathrm{dph}$, respectively. The CG-DMRs, CHG-DMRs and CHH-DMRs were located in 44,459, 1128 and 9572 genes, respectively. The vast majority of DMRs (95.7\%) were in the CG context, while only $4.3 \%$ DMRs were in CHG and $\mathrm{CHH}$.

DMRs-related genes were analyzed using KEGG database. In gene body region, 304, 241 and 297 pathways were identified from CG-DMRs, CHG-DMRs and CHH-DMRs, respectively. Furthermore, in promoter region, 302, 75 and 226 pathways were identified from CG-DMRs, CHGDMRs and CHH-DMRs, respectively. The top 20 pathways in ascending order of corrected $p$ value were listed in Additional file 4. To investigate pathways and processes that may be subject to epigenetic variation in association with DMRs, we conducted a GO enrichment analysis. It is revealed that genes involved in GO terms such as cellular process, biological regulation, metabolic process, binding, catalytic activity, and response to stimulus were significantly over-represented. The top $60 \mathrm{GO}$ terms were listed in Additional file 5 by ascending order of corrected $\mathrm{p}$ value.

\section{Validation of target DMGs by real-time $\mathrm{qPCR}$}

The present study focused on the mTOR signaling pathway. According to the bisulfite sequencing, we found 


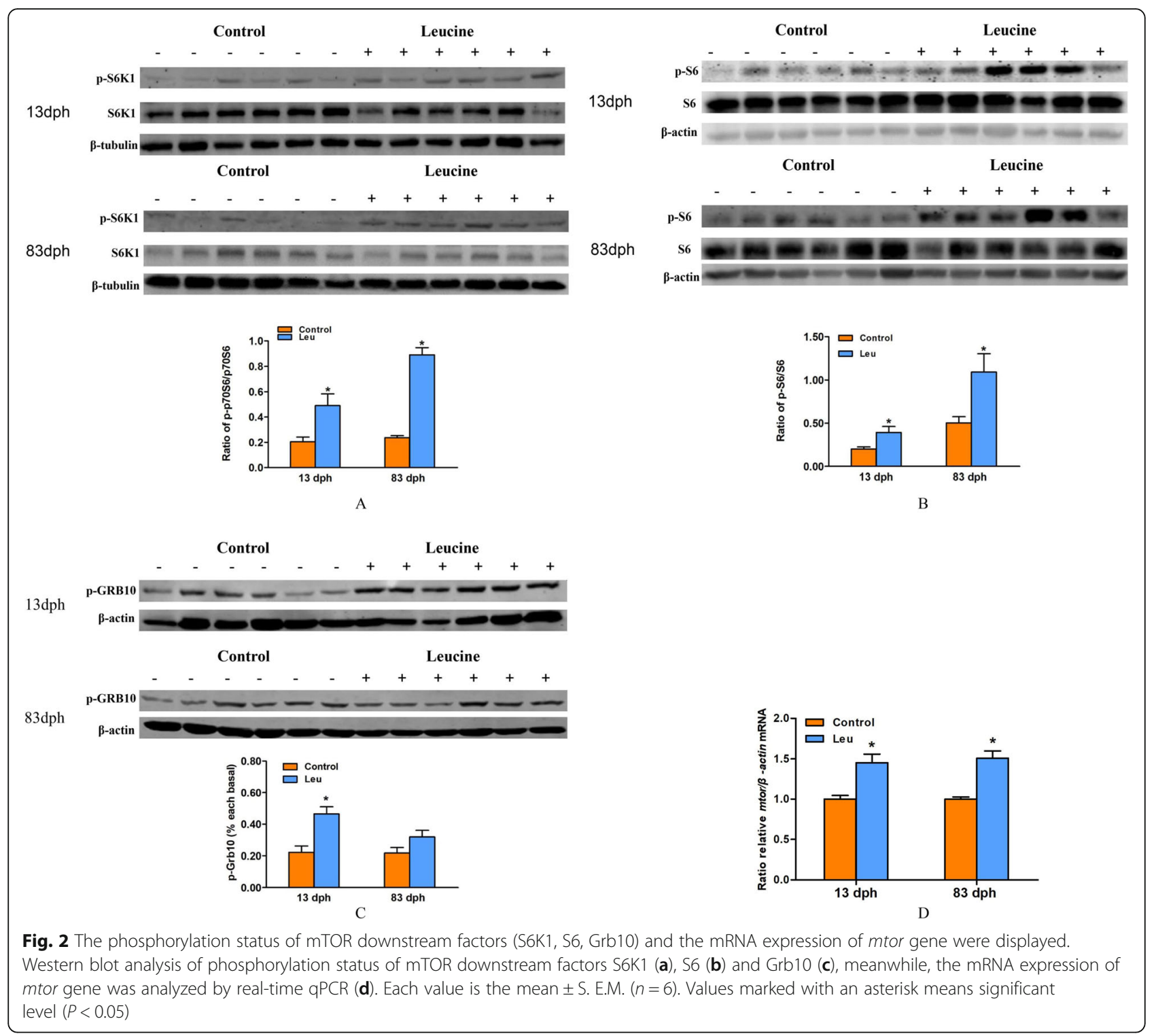

that 28 CG-DMGs (such as mTOR, Deptor, eIF4E, $4 E-$ $B P$, Grb10, $m L S T 8$ and SGK1) involved in mTOR signaling pathway, exhibited the lower levels of DNA methylation in fish of the leucine programming group than those of the control group (Fig. 5a). Meanwhile, we also found that 21 CHH-DMGs (such as mTOR, Grb10, GATOR1, GATOR2 and eIF4E) involved in mTOR signaling pathway, exhibited the higher levels of DNA methylation in fish of the leucine programming group than those of the control group (Fig. 5b).

The changes of methylation levels in genomic regions could be associated with the differential expression of genes. To analyze the expression of the DMGs in mTOR signaling pathway, the real-time qPCR was carried out for four DMGs in fish from the leucine programming group and control group. As shown in Fig. 6a, the
mRNA levels of Grb10, eIF4E and mTOR genes were significantly higher in fish of the leucine programming group than those of the control group $(P<0.05)$. Meanwhile, the methylation status of Grb10, eIF4E, mTOR and $W d r 24$ genes in CG and $\mathrm{CHH}$ types were shown in Fig. $6 \mathrm{~b}$ and c.

\section{Discussion}

Several studies in mammals reported that nutrient and metabolic programming during the critical periods of early development might result in the long-term genetic and physiological consequences during adulthood [1, 29-31]. The concept of early nutritional programming has been applied to improve the nutrient utilization in adult fish $[3,4,6]$. However, no effect is recorded for nutritional programming of amino acids. In the present 

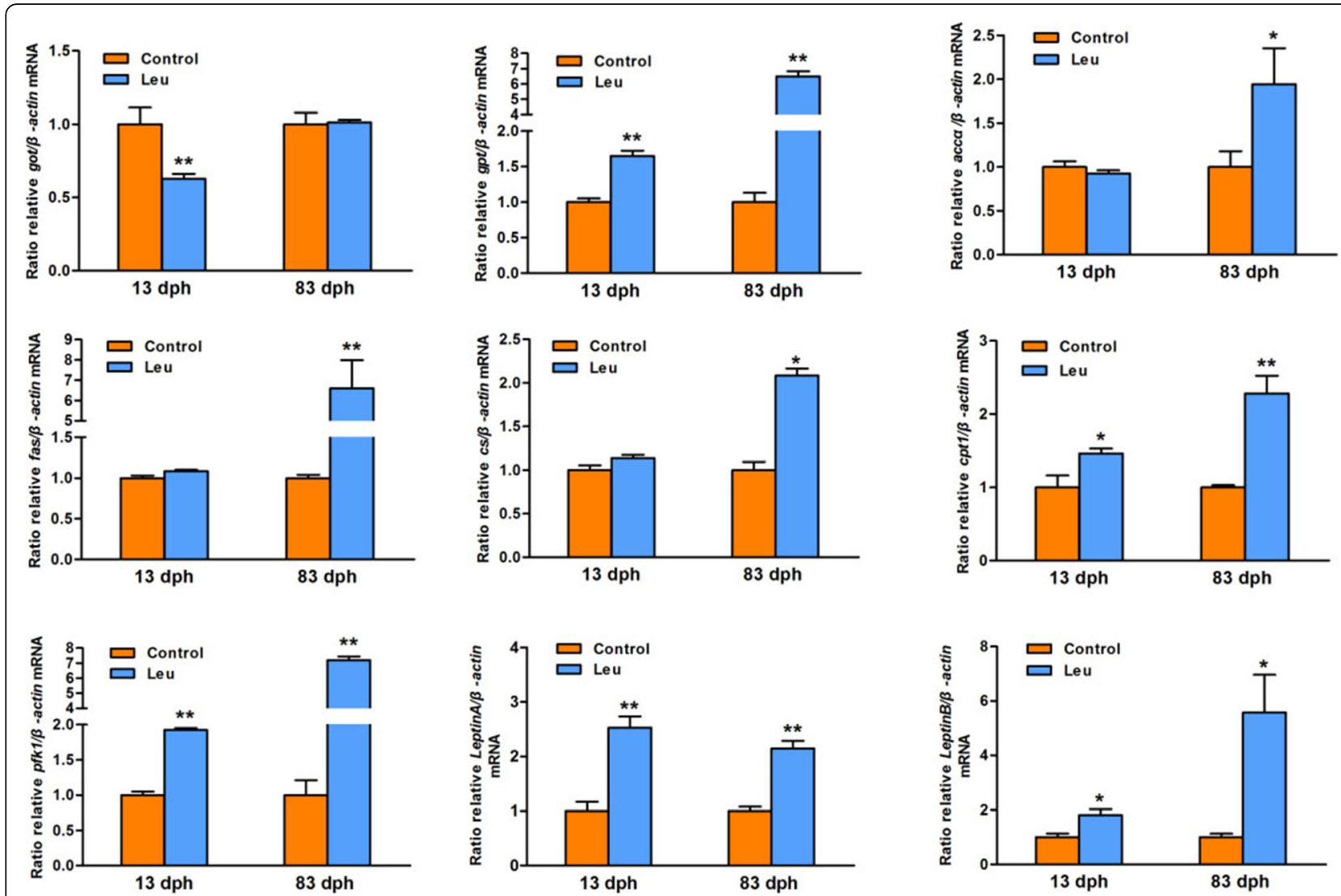

Fig. 3 The mRNA expression of genes related to metabolism. The value represented mean \pm S. E.M. $(n=6)$, marked with an asterisk means significant level $(P<0.05)$, marked with two asterisk means extremely significant level $(P<0.01)$

study, we attempted to treat zebrafish larvas with leucine at early developmental stage for assessing the short-term and long-term modifications of early leucine programming on growth and nutritional utilization.

Leucine participates in the regulation of protein metabolism through mTOR signaling pathway [32, 33]. However, it has not yet been determined if leucine could improve the growth and nutritional utilization by early stimulation. The leucine level in whole-body of zebrafish after early leucine programming was significantly higher than that of the control group at $13 \mathrm{dph}$, suggesting that the treatment of $1 \%$ leucine could change the leucine content of zebrafish. Zebrafish larvas were treated with leucine from $3 \mathrm{dph}$ to $13 \mathrm{dph}$, and the growth was significantly better than those in the control group at 13 and $83 \mathrm{dph}$. Previous study reported that the growth and survival rate were affected by neither early glucose stimulus nor dietary challenge with high carbohydrates [34]. Early hyperglucidic stimulation had no significant effect on body weight in rainbow trout and zebrafish during a long experimental period [3, 6]. However, an early stimulus of high carbohydrate diet (60\%) at firstfeeding can lead to the detrimental effects in the longterm growth performance [35]. In the present study, the early leucine programming could markedly promote the growth of zebrafish at both early developmental stage and adult stage. By the body composition analysis at 83 $\mathrm{dph}$, we found that the crude protein content of zebrafish with early leucine programming was increased, while the crude lipid was decreased, and the total water showed no difference. The study in gilthead seabream (Sparus aurata) juvenile, showed that early glucose stimuli at the larval stage has the positive effect on lipid retention, but not on protein saving [36]. However, it is suggested that early leucine programming could effectively improve the growth of zebrafish, which might be attributed to the increased protein synthesis and lipid decomposition.

Leucine activates the utilization of amino acids for protein synthesis and inhibits protein catabolism through mTOR pathway $[12,37]$. To investigate whether early leucine programming in zebrafish can promote the growth and protein synthesis through activating mTOR pathway. We examined the phosphorylation status of mTOR downstream factors S6K1, S6 and Grb10, and found that the early leucine programming could continuously activate the mTOR signaling pathway at both 13 and $83 \mathrm{dph}$, with higher phosphorylation status of 

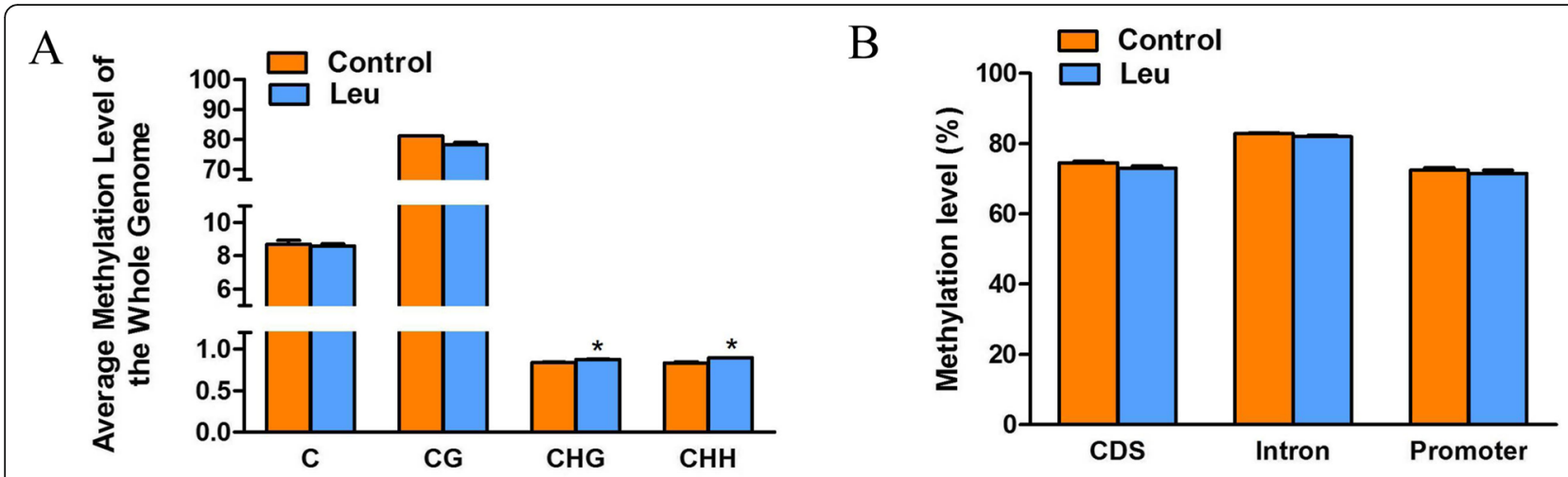

C

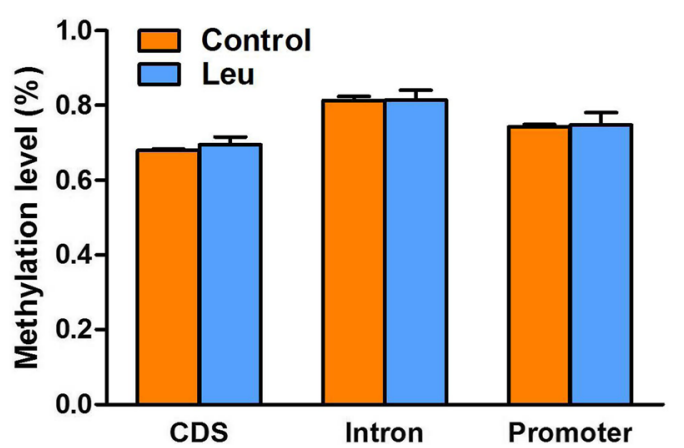

$\mathrm{D}$

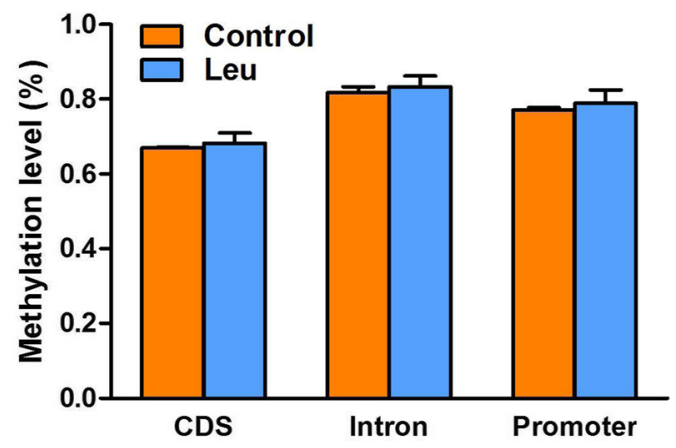

Fig. 4 The average genome-wide methylation levels (a) and DNA methylation levels of different genomic regions (b-d). The value represented the mean \pm S. E.M. $(n=3)$, marked with an asterisk means significant level $(P<0.05)$. A: $X$-axis represented methylation types, $Y$-axis represented average genome-wide methylation levels. B: X-axis represented genomics features, Y-axis represented methylation levels. b CG regions, c CHG regions, (d) $\mathrm{CHH}$ regions

S6K1 and S6. In addition, the mRNA level of mtor gene was also increased in the leucine programming group, suggesting the activation of mTOR signaling. The leucine in the diet plays an important role in regulating growth performance, body composition, and mTOR signaling pathways in fish [14, 38, 39]. With the injection of leucine in the hypothalamus of rainbow trout, the mTOR signaling pathway in central nervous system is activated, thereby regulating the digestion and absorption of nutrients [15]. In rainbow trout hepatocytes, amino acids up-regulate the protein synthesis by activating mTOR signaling pathway $[16,17]$. We therefore surmised that the early leucine programming could effectively activate the mTOR signaling pathway, which might promote protein synthesis in a long-term period of zebrafish.

In juvenile blunt snout bream (Megalobrama amblycephala), dietary leucine supplement can affect glucose metabolism and lipogenesis involved in MTOR signaling pathway [40]. To study the effect of early leucine stimulation on nutritional metabolism, we analyzed the mRNA expression of genes related to nutritional metabolism in zebrafish. GOT and GPT are the important amino acid-degrading enzymes, and their activities positively correlated to dietary protein levels in Jian carp (Cyprinus carpio var. Jian) [41]. With the early leucine programming, the gpt mRNA expression was upregulated in the zebrafish at $83 \mathrm{dph}$, whereas the got was not significantly affected. The gene expressions of lipogenesis enzymes ( $a c c \alpha$, fas and $c s$ ) were increased with the early leucine programming, and the gene expression of fat $\beta$-oxidation key enzyme (cpt1) was also significantly increased, suggesting that the early leucine programming could accelerate the synthesis and oxidative decomposition of lipid, improving the utilization of lipid. In rainbow trout hepatocytes, leucine could activate the mTOR signaling pathway to up-regulate the gene expression of fas, promoting lipid synthesis [16]. In addition, for glucose metabolism, the mRNA level of glycolysis gene (pfk1) was also significantly elevated by the early leucine programming. We also found a significant up-regulation of leptin $A$ and $B$ in the leucine programming group. Leptin signaling regulates glucose homeostasis but is not an adipostatic factor in zebrafish [42]. mTORC1 is sufficient to affect metabolic pathways by activation of a transcriptional program for metabolic gene targets of 


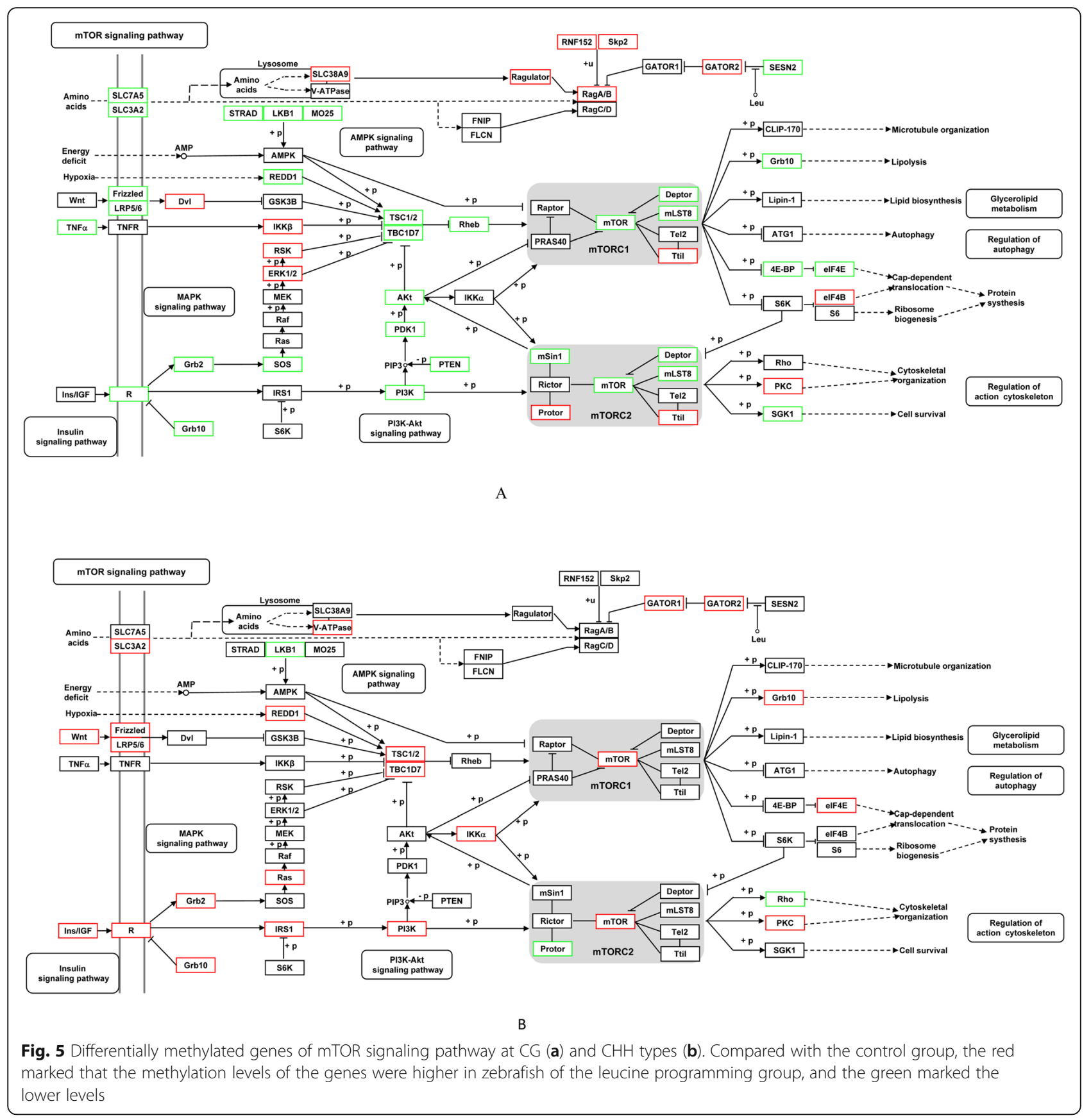

sterol regulatory element-binding protein (SREBP), including glycolysis, pentose phosphate pathway and lipid biosynthesis [43]. Therefore, early leucine stimulation could increase the phosphorylation level of protein S6K1 and S6, as the regulatory signaling of mTOR pathway, promoting protein synthesis and growth. Meanwhile, the glucose and lipid metabolism were also significantly enhanced, which might be related to mTOR signaling, in zebrafish with early leucine programming.

There are increasing evidences that the early environmental stimulation might cause changes in organisms via epigenetic modification. Previous study in Nile tilapia (Oreochromis niloticus) gonads has observed the DNA methylation changes on a genome-wide scale after earlier high-temperature induction [44]. Zebrafish embryos are exposed to androgens (testosterone and dihydrotestosterone) early at 26 to $56 \mathrm{~h}$ post fertilization, resulting in transgenerational alterations in the zebrafish ovarian epigenome [45]. In the present study, early leucine stimulation led to the long-term changes of gene expression in zebrafish. We compared the genome-wide methylation patterns between the control and leucine 

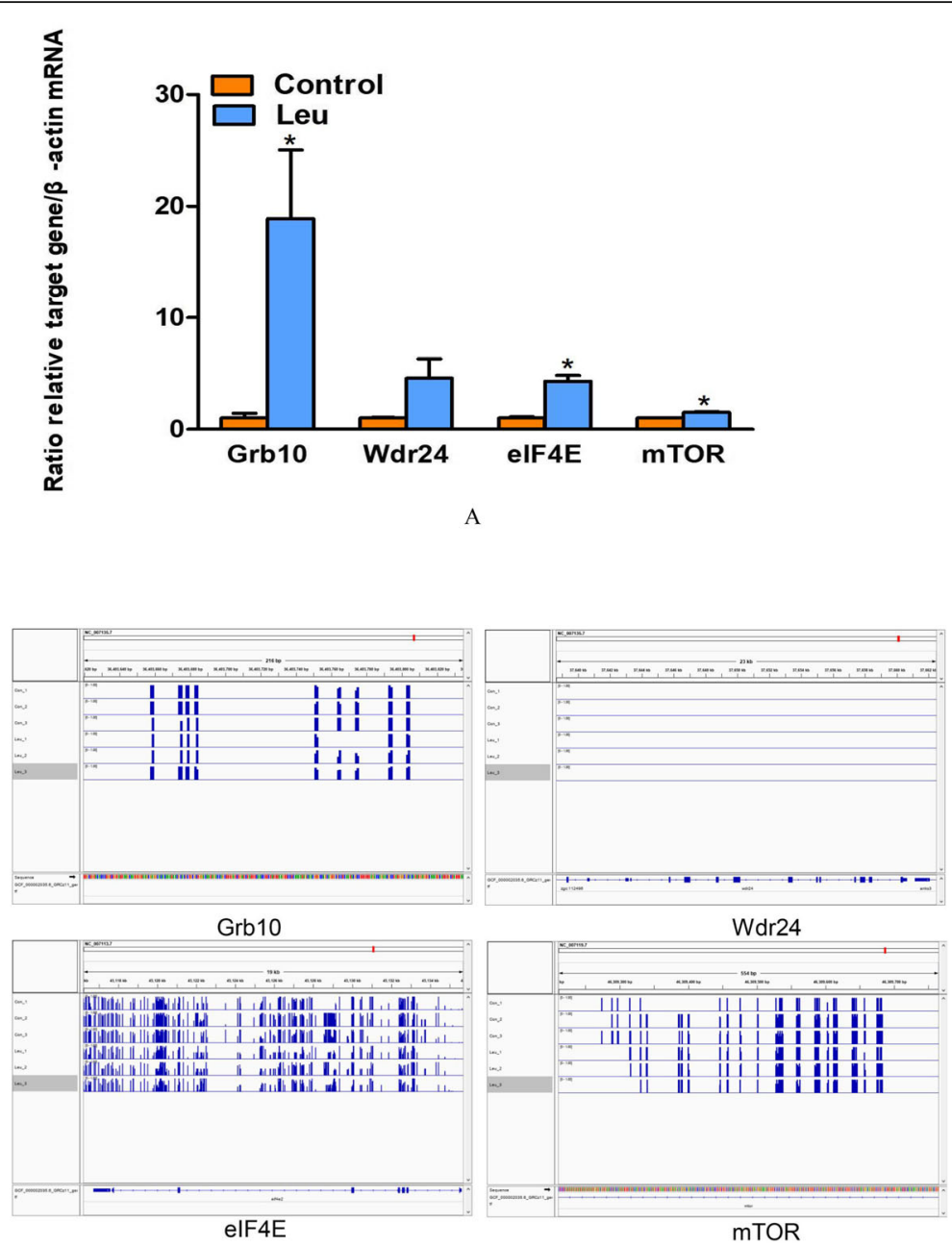

B
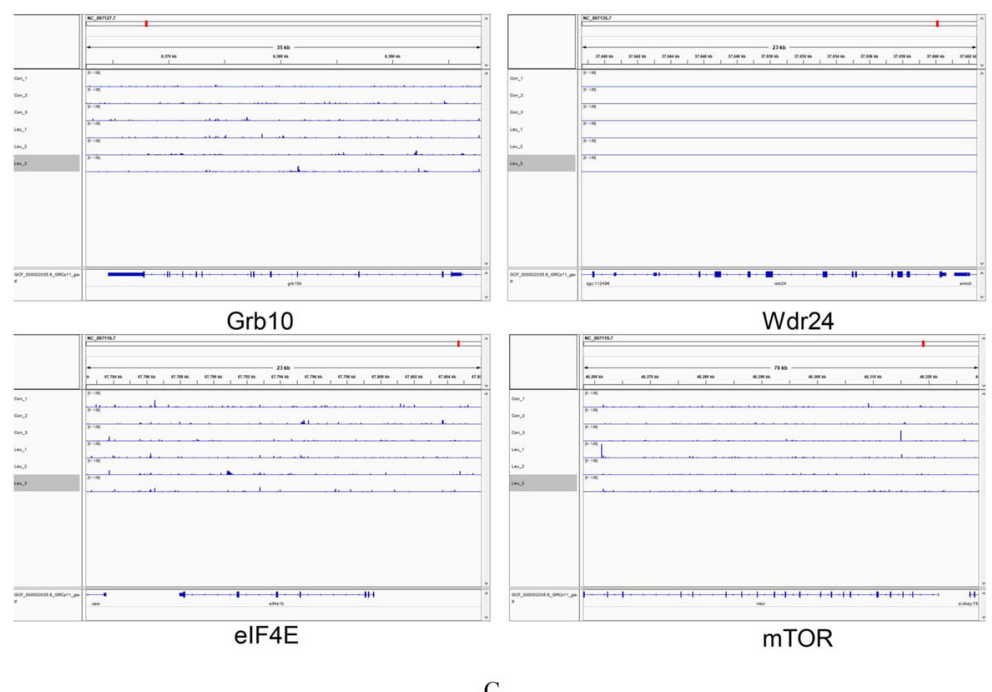

Fig. 6 (See legend on next page.) 
(See figure on previous page.)

Fig. 6 The mRNA expression (a), the methylation status in CG (b) and CHH (c) type of DMGs involved in mTOR signaling pathway. All qRT-PCR reactions were performed with six biological replicates, the value represented the mean \pm S. E.M. marked with an asterisk means significant level $(P<0.05)$. Displayed DNA methylation status of Grb10, elF4E, mTOR and Wdr24 by IGV tool. Con-1, Con-2, Con-3: samples of the control group; Leu-1, Leu-2, Leu-3: samples of the leucine programming group

programming zebrafish. The methylation level of CpGs in zebrafish liver was above $70 \%$, similar to those found in zebrafish and tilapia [46, 47]. The total DNA methylation level of $\mathrm{CHG}$ and $\mathrm{CHH}$ methylation types in fish of the leucine programming group was higher than those of the control group. In addition, we identified the pathways associated with energy metabolism in early leucine programming. Among these pathways, the mTOR signaling pathway is an attractive target, because it plays an important role in the integration between amino acid and energy-sensing pathways [48]. The most genes of mTOR pathway were hypomethylated (lower methylation) for CG type and hypermethylated (higher methylation) for $\mathrm{CHH}$ type in the leucine stimulation group compared with the control group. These results suggested that the patterns of DNA methylation could be highly plastic and react to the cues of early nutrition induction.

To highlight the potential role of methylation of key genes in mTOR signaling pathway with early leucine programming, we examined the mRNA expression of four genes in mTOR signaling pathway, including Grb10, eIF4E, mTOR and Wdr24. The result showed the increased mRNA expression of Grb10, eIF4E and mTOR genes in the zebrafish with early leucine programming. Grb10 is a key regulator of the mTORC1 signaling pathways on lipid metabolism [49]. The enhanced phosphorylation state of eukaryotic initiation factor 4E-binding protein 1 (4E-BP1) induced by administration of leucine stimulates protein synthesis by accelerating translation initiation [50]. We suggested that the decreased methylation in CG type and increased methylation in $\mathrm{CHH}$ type of Grb10, eIF4E and mTOR genes, could contribute to their enhanced gene expressions. There are complex relationships between DNA methylation and gene expression. Generally, DNA methylation in promoters is negatively associated with gene expression. In Nile tilapia, high temperature increases the DNA methylation level and decreases the mRNA expression of cyp19a1a gene [51]. However, studies have also shown that DNA methylation is not necessarily associated with the repression of gene expression, but exhibits the positive correlations with transcription activation instead [52]. In the study of Brassica napus, the gene expression of BnaA0724700D and BnaA08g08410D are up-regulated, although they exhibit opposite methylation patterns in their promoters [53]. In the present study, the increased methylation in $\mathrm{CHH}$ type were at the gene body region of Grb10, eIF4E and $m T O R$ genes. Therefore, we speculated that the enhanced expression of Grb10, eIF4E and $m T O R$ genes in the zebrafish with early leucine programming might be more possibly attributed to the decreased methylation in CG type at the gene promotor regions. The study of genome-wide methylome has emphasized that the promoter methylation is closely related to gene regulation [54].

\section{Conclusions}

For the first time, we used the DNA methylation profiling to elucidate the regulatory mechanism of early amino acid programming on nutritional utilization. We found that the DNA methylation of genes involved in mTOR signaling pathway may contribute to the activation of mTOR signaling, promoting protein synthesis and growth of zebrafish with early leucine programming. In addition, early leucine programming could enhance the mRNA expressions of genes related to glycolipid metabolism. The present study may be beneficial for better understanding the epigenetic regulation in nutrition metabolism by early programming.

\section{Supplementary information}

Supplementary information accompanies this paper at https://doi.org/10. 1186/s12986-020-00487-3.

Additional file 1. Sequencing data by whole genome bisulfite sequencing (WGBS).

Additional file 2. Comparison of DNA methylation patterns between the two groups.

Additional file 3. DNA methylation levels across genomic elements. The abscissa represented different functional elements that $a, b, c, d, e, f$ and g denoted upstream, first exon, first intron, inner exon, inner intron, last exon and downstream, respectively. The left ordinate represented the mean methylation levels of $C G$, and the right ordinate represented the mean methylation levels of $\mathrm{CHG} / \mathrm{CHH}$. The dotted, green, vertical line represented the TSS, and the red, orange and blue solid lines represented $\mathrm{CG}, \mathrm{CHH}$ and $\mathrm{CHG}$, respectively, which showed the methylation levels fluctuating in the different regions.

Additional file 4 Scatterplot of enriched KEGG pathways for the differentially methylated genes in promoter and gene body regions. The ordinate represented the enriched pathways, and the abscissa represented the rich factor of corresponding pathways; the size of the spots represented the number of genes related to DMRs enriched in each pathway, while the color of the spot represented the corrected $p$ value of each pathway.

Additional file 5. Gene ontology functional annotations for the differentially methylated genes. All GO terms were divided into three categories: blue refer to biological process, green refer to cell

components, and red refer to molecular function. The ordinate represents three domains of $\mathrm{GO}$ while abscissa represents the gene number in every pathway and processes. 


\section{Abbreviations}

dph: Days post hatching; Grb10: Growth factor receptor-bound protein 10; elF4E: Eukaryotic translation initiation factor 4E; mTOR: Mechanistic target of rapamycin; S6: Ribosomal protein S6; S6K1: Ribosomal protein S6 kinase 1; WGBS: Whole genome bisulfite sequencing; DMRs: Differentially methylated regions; IGV: Integrative Genomics Viewer; cpt1: Carnitine palmitoyl transferase I; pfk1: Phosphofructo kinase I; gpt: Glutamic-pyruvic transaminase; cs: Citrate synthase; acca: Acetyl-CoA carboxylase alpha; fas: Fatty acid synthase; Wdr24: WD repeat-containing protein 24; SREBP: Sterol regulatory element-binding protein; 4E-BP1: 4E-binding protein 1; BSMAP: Bisulfite Sequence Mapping Program; KEGG: Kyoto Encyclopedia of Genes and Genomes; SRA: Sequence Read Archive

\section{Acknowledgments}

Not applicable.

\section{Authors' contributions}

Q. S. Z., J. W., S. H., X. F. L., S. X. and Q. O. X. contributed to the sample preparation and examination. Q. S. Z and S. H performed the assembly and bioinformatical analysis. Q. S. Z., J. W., S. H., S. X. and Q. Q. X. performed the data analysis. S. H and X. F. L gave technical advice and contributed to the study design. Q. S. Z and S. H wrote the paper. All authors read and approved the final manuscript

\section{Funding}

This work was financially supported by National Key R\&D Program of China (No. 2018YFD0900400), the Da Bei Nong Group Promoted Project for Young Scholar of HZAU (No. 2017DBN014) and the National Natural Science Foundation of China (No. 31602131).

\section{Availability of data and materials}

The sequencing data in this study have been deposited in the Sequence Read Archive (SRA) database (accession number: SUB6149613 and PRJNA559591). The datasets used and/or analyzed during the current study are available from the corresponding author on reasonable request.

\section{Ethics approval and consent to participate}

All zebrafish and experiments were performed in accordance with the "Guidelines for Experimental Animals" of the Ministry of Science and Technology (Beijing, China). The study was approved by the Institutional Animal Care and Use Ethics Committee of Huazhong Agricultural University. All efforts were made to minimize suffering.

\section{Consent for publication}

Not applicable.

\section{Competing interests}

The authors declare that they have no competing interests.

Received: 4 July 2020 Accepted: 3 August 2020

Published online: 14 August 2020

\section{References}

1. Lucas A. Programming by early nutrition an experimental approach. J Nutr. 1998;128:401S-6S.

2. Reynolds CM, Gray C, Li M, Segovia SA, Vickers MH. Early life nutrition and energy balance disorders in offspring in later life. Nutrients. 2015;7:8090111.

3. Geurden I, Aramendi M, Zambonino-Infante J, Panserat S. Early feeding of carnivorous rainbow trout (Oncorhynchus mykiss) with a hyperglucidic diet during a short period: effect on dietary glucose utilization in juveniles. Am J Physiol Regul Integr Comp Physiol. 2007;292:R2275-83.

4. Vagner M, Robin JH, Zambonino Infante JL, Person-Le RJ. Combined effects of dietary HUFA level and temperature on sea bass (Dicentrarchus labrax) larvae development. Aquaculture. 2007:266:179-90.

5. Vagner M, Robin JH, Zambonino-Infante JL, Tocher DR, Person-Le Ruyet J. Ontogenic effects of early feeding of sea bass (Dicentrarchus labrax) larvae with a range of dietary $n-3$ highly unsaturated fatty acid levels on the functioning of polyunsaturated fatty acid desaturation pathways. Br J Nutr. 2009;101:1452-62.
6. Fang L, Liang XF, Zhou Y, Guo XZ, He Y, Yi TL, Liu LW, Yuan XC, Tao YX. Programming effects of high-carbohydrate feeding of larvae on adult glucose metabolism in zebrafish, Danio rerio. Br J Nutr. 2014;111(5):808-18.

7. McMillen IC, Robinson JS. Developmental origins of the metabolic syndrome: prediction, plasticity, and programming. Physiol Rev. 2005;85: 571-633.

8. Luo L, Wei H, Ai L, Liang X, Wu X, Xing W, Chen P, Xue M. Effects of early long-chain n-3HUFA programming on growth, antioxidant response and lipid metabolism of Siberian sturgeon (Acipenser baerii Brandt). Aquaculture. 2019:509:96-103.

9. Geurden I, Mennigen J, Plagnes-Juan E, Veron V, Cerezo T, Mazurais D, Zambonino-Infante J, Gatesoupe J, Skiba-Cassy S, Panserat S. High or low dietary carbohydrate:protein ratios during first-feeding affect glucose metabolism and intestinal microbiota in juvenile rainbow trout. J Exp Biol. 2014;217:3396-406.

10. Liu J, Dias K, Plagnes-Juan E, Veron V, Panserat S, Marandel L. Long-term programming effect of embryonic hypoxia exposure and high-carbohydrate diet at first feeding on glucose metabolism in juvenile rainbow trout. J Exp Biol. 2017;220:3686-94

11. Li $F$, Yin $Y$, Tan B, Kong $X$, Wu G. Leucine nutrition in animals and humans: mTOR signaling and beyond. Amino Acids. 2011;41:1185-93.

12. Ahmed I, Khan MA. Dietary branched-chain amino acid valine, isoleucine and leucine requirements of fingerling Indian major carp, Cirrhinus mrigala (Hamilton). Br J Nutr. 2006;96:450-60.

13. Abidi SF, Khan MA. Dietary leucine requirement of fingerling Indian major carp, Labeo rohita (Hamilton). Aquac Res. 2007;38:478-86.

14. Deng YP, Jiang WD, Liu Y, Jiang J, Kuang SY, Tang L, Wu P, Zhang YA, Feng $L$, Zhou XQ. Differential growth performance, intestinal antioxidant status and relative expression of Nrf2 and its target genes in young grass carp (Ctenopharyngodon idella) fed with graded levels of leucine. Aquaculture. 2014:434:66-73.

15. Comesana S, Velasco C, Ceinos RM, Lopez-Patino MA, Miguez JM, Morais S, Soengas $J$ L. Evidence for the presence in rainbow trout brain of amino acidsensing systems involved in the control of food intake. Am J Physiol Regul Integr Comp Physiol. 2018;314:R201-15.

16. Lansard M, Panserat S, Plagnes-Juan E, Seiliez I, Skiba-Cassy S. Integration of insulin and amino acid signals that regulate hepatic metabolism-related gene expression in rainbow trout: role of TOR. Amino Acids. 2010;39:801-10.

17. Lansard M, Panserat S, Plagnes-Juan E, Dias K, Seiliez I, Skiba-Cassy S. Lleucine, L-methionine, and L-lysine are involved in the regulation of intermediary metabolism-related gene expression in rainbow trout hepatocytes. J Nutr. 2011;141:75-80.

18. Nijland MJ, Mitsuya K, Li C, Ford S, McDonald TJ, Nathanielsz PW, Cox LA. Epigenetic modification of fetal baboon hepatic phosphoenolpyruvate carboxykinase following exposure to moderately reduced nutrient availability. J Physiol. 2010;588:1349-59.

19. Burdge GC, Hoile SP, Uller T, Thomas NA, Gluckman PD, Hanson MA, Lillycrop KA. Progressive, transgenerational changes in offspring phenotype and epigenotype following nutritional transition. PLoS One. 2011;6(11):e28282.

20. He XJ, Chen T, Zhu JK. Regulation and function of DNA methylation in plants and animals. Cell Res. 2011:21:442-65.

21. Smith ZD, Meissner A. DNA methylation: roles in mammalian development. Nat Rev Genet. 2013;14:204-20.

22. Waterland R, Jirtle R. Early nutrition, epigenetic changes at transposons and imprinted genes, and enhanced susceptibility to adult chronic diseases. Nutrition. 2004;20:63-8.

23. Zeisel $\mathrm{SH}$. Epigenetic mechanisms for nutrition determinants of later health outcomes. Am J Clin Nutr. 2009;89:1488S-93S.

24. Veron V, Marandel L, Liu J, Velez EJ, Lepais O, Panserat S, Skiba S, Seiliez I. DNA methylation of the promoter region of bnip3 and bnip3l genes induced by metabolic programming. BMC Genomics. 2018;19:677.

25. Goetz FW, Donaldson EM, Hunter GA, Dye HM. Effects of estradiol-17 $\beta$ and

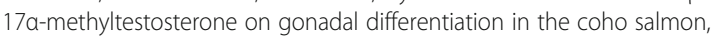
Oncorhynchus kisutch. Aquaculture. 1979;17:267-78.

26. Zeng YH, Cai WS, Shao XG. Quantitative analysis of 17 amino acids in tobacco leaves using an amino acid analyzer and chemometric resolution. J Separation Sci. 2015;38(12):2053-8.

27. Horwitz W. Official methods of analysis of the Association of Official Analytical Chemists. J Pharm Sci. 1975;60:414.

28. Livak KJ, Schmittgen TD. Analysis of relative gene expression data using real-time quantitative PCR and the $2^{-\Delta \Delta C T}$ method. Methods. 2001;25:402-8. 
29. Demmelmair H, von Rosen J, Koletzko B. Long-term consequences of early nutrition. Early Hum Dev. 2006;82:567-74.

30. Hall W. Weaning and growth of artificially reared rats. Science. 1975;190: 1313-5.

31. Patel MS, Srinivasan M, Laychock SG. Metabolic programming: role of nutrition in the immediate postnatal life. J Inherit Metab Dis. 2009;32:218-28.

32. Escobar J, Frank JW, Suryawan A, Nguyen HV, Davis TA. Amino acid availability and age affect the leucine stimulation of protein synthesis and elF4F formation in muscle. Am J Physiol Endocrinol Metab. 2007;293:E1615-21.

33. Suryawan A, Jeyapalan AS, Orellana RA, Wilson FA, Nguyen HV, Davis TA. Leucine stimulates protein synthesis in skeletal muscle of neonatal pigs by enhancing mTORC1 activation. Am J Physiol Endocrinol Metab. 2008;295: E868-75.

34. Rocha F, Dias J, Engrola S, Gavaia P, Geurden I, Dinis MT, Panserat S. Glucose metabolism and gene expression in juvenile zebrafish (Danio rerio) challenged with a high carbohydrate diet: effects of an acute glucose stimulus during late embryonic life. Br J Nutr. 2015;113:403-13.

35. Liu J, Plagnes-Juan E, Geurden I, Panserat S, Marandel L. Exposure to an acute hypoxic stimulus during early life affects the expression of glucose metabolism-related genes at first-feeding in trout. Sci Rep. 2017;7:363.

36. Rocha F, Dias J, Geurden I, Dinis MT, Panserat S, Engrola S. Dietary glucose stimulus at larval stage modifies the carbohydrate metabolic pathway in gilthead seabream (Sparus aurata) juveniles: An in vivo approach using (14) C-starch. Comp Biochem Physiol A Mol Integr Physiol. 2016;201:189-99.

37. Guertin DA, Guntur KV, Bell GW, Thoreen CC, Sabatini DM. Functional genomics identifies TOR-regulated genes that control growth and division. Curr Biol. 2006;16:958-70.

38. Ren M, Habte-Tsion H-M, Liu B, Miao L, Ge X, Xie J, Liang H, Zhou Q, Pan L. Dietary leucine level affects growth performance, whole body composition, plasma parameters and relative expression of TOR and TNF-a in juvenile blunt snout bream, Megalobrama amblycephala. Aquaculture. 2015;448:162-8.

39. Liang H, Mokrani A, Chisomo-Kasiya H, Ji K, Ge X, Ren M, Liu B, Xi B, Sun A Dietary leucine affects glucose metabolism and lipogenesis involved in TOR/PI3K/Akt signaling pathway for juvenile blunt snout bream Megalobrama amblycephala. Fish Physiol Biochem. 2019;45:719-32.

40. Ramaswamy M, Thangavel P, Selvam N. Glutamic oxaloacetic transaminase (GOT) and glutamic pyruvic transaminase (GPT) enzyme activities in different tissues of Sarotherodon mossambicus (Peters) exposed to a carbamate pesticide, carbaryl. Pestic Sci. 1999;55:1217-21.

41. Michel M, Page-McCaw PS, Chen W, Cone RD. Leptin signaling regulates glucose homeostasis, but not adipostasis, in the zebrafish. Proc Natl Acad Sci U S A. 2016;113:3084-9.

42. Düvel K, Yecies JL, Menon S, Raman P, Lipovsky Al, Souza AL, Triantafellow E, Ma Q, Gorski R, Cleaver S, Vander Heiden MG, MacKeigan JP, Finan PM, Clish $\mathrm{CB}$, Murphy LO, Manning BD. Activation of a metabolic gene regulatory network downstream of mTOR complex 1. Mol Cell. 2010;39:171-83.

43. Sun LX, Wang YY, Zhao Y, Wang H, Li N, Ji XS. Global DNA methylation changes in Nile Tilapia gonads during high temperature-induced masculinization. PLoS One. 2016;11:e0158483.

44. Xu N, Chua AK, Jiang H, Liu NA, Goodarzi MO. Early embryonic androgen exposure induces transgenerational epigenetic and metabolic changes. Mol Endocrinol. 2014;28:1329-36.

45. Potok ME, Nix DA, Parnell TJ, Cairns BR. Reprogramming the maternal zebrafish genome after fertilization to match the paternal methylation pattern. Cell. 2013;153:759-72.

46. Chatterjee A, Stockwell PA, Horsfield JA, Morison IM, Nakagawa S. Baseresolution DNA methylation landscape of zebrafish brain and liver. Genom Data. 2014:2:342-4

47. Wan ZY, Xia JH, Lin G, Wang L, Lin VC, Yue GH. Genome-wide methylation analysis identified sexually dimorphic methylated regions in hybrid tilapia. Sci Rep. 2016;6:35903.

48. Tokunaga C, Yoshino K, Yonezawa K. mTOR integrates amino acid and energy-sensing pathways. Biochem Biophys Res Commun. 2004;313:443-6.

49. Liu B, Liu F. Feedback regulation of mTORC1 by Grb10 in metabolism and beyond. Cell Cycle. 2014;13:2643-4.

50. Yoshizawa F, Sekizawa H, Hirayama S, Hatakeyama A, Nagasawa T, Sugahara $\mathrm{K}$. Time course of Leucine-induced 4E-BP1 and S6K1 phosphorylation in the liver and skeletal muscle of rats. J Nutr Sci Vitaminol. 2001;47:311-5.

51. Wang YY, Sun LX, Zhu JJ, Zhao Y, Wang H, Liu HJ, Ji XS. Epigenetic control of cyp19a1a expression is critical for high temperature induced Nile tilapia masculinization. J Therm Biol. 2017;69:76-84.
52. Jones PA. Functions of DNA methylation: islands, start sites, gene bodies and beyond. Nat Rev Genet. 2012;13:484-92.

53. Wang Z, Wu X, Wu Z, An H, Yi B, Wen J, Ma C, Shen J, Fu T, Tu J. Genomewide DNA methylation comparison between Brassica napus genic male sterile line and restorer line. Int J Mol Sci. 2018;19:2689.

54. Ma X, Yang Q, Wilson KT, Kundu N, Meltzer SJ, Fulton AM. Promoter methylation regulates cyclooxygenase expression in breast cancer. Breast Cancer Res. 2004:6:R316.

\section{Publisher's Note}

Springer Nature remains neutral with regard to jurisdictional claims in published maps and institutional affiliations.

\section{Ready to submit your research? Choose BMC and benefit from:}

- fast, convenient online submission

- thorough peer review by experienced researchers in your field

- rapid publication on acceptance

- support for research data, including large and complex data types

- gold Open Access which fosters wider collaboration and increased citations

- maximum visibility for your research: over $100 \mathrm{M}$ website views per year

At BMC, research is always in progress.

Learn more biomedcentral.com/submissions 